\title{
International Handbook for Emergency Response to Flood Risk: A call for collaboration
}

\author{
Bart Vonk ${ }^{1, a}$, Wout de Vries ${ }^{1}$, Eric van Kuijk ${ }^{1}$, Marcel Bottema ${ }^{1}$, Ludolph Wentholt ${ }^{2}$, Eric Huijskes ${ }^{3}$ \\ ${ }^{1}$ Rijkswaterstaat, PO Box 2232, 3500 GE Utrecht, The Netherlands \\ 2 STOWA, PO Box 2180, 3800 CD Amersfoort, The Netherlands \\ ${ }^{2}$ Huijskes Advies BV, Joelaan 1, 1217GG Hilversum, The Netherlands
}

\begin{abstract}
.
Flood emergency response is an essential component of a flood risk management strategy. Effective flood emergency response depends on implementing the appropriate measures, and on executing them correctly. The skills and expertise of emergency management teams play a crucial role in this response. It is crucial that all involved work along commonly agreed lines. To achieve this, an initiative is launched to arrive at an International Handbook for Emergency Response to Flood Risk. This handbook will provide these "commonly agreed lines", covering flood emergency response management in general and will include topics such as failure mechanisms, techniques for intervention, logistics and health \& safety. It will showcase good practices and will share lessons learnt from flood emergency response approaches all over the world. In this way it will be an invaluable tool to train staff in the operation of flood fighting and to ascertain that the assistance from (international) flood fighting colleagues is at the appropriate level.

During the FLOODrisk 2020 Conference, a first framework of this International Handbook is presented and discussed with the participants to ensure the framework meets their needs. We will extend an invitation to participants to provide suggestions and to join forces in this initiative. We are aiming to formalise this initiative towards the end of 2021.
\end{abstract}

\section{Introduction}

Flood risk can be managed by using various strategies, ranging from prevention, protection by flood defences, through spatial planning and by responding to the flood emergency at hand. Internationally the Associated Programme on Flood Management (APFM), a joint initiative of the World Meteorological Organization (WMO) and the Global Water Partnership (GWP), provides guidance. It promotes the concept of Integrated Flood Management (IFM; WMO, 2009) as an effective approach to flood management. It goes without saying that full protection is not possible and that additional reliance on preparedness and emergency response is inevitable. Throughout the world, there are different approaches to emergency response to minimize flood risk. Also, experiences implementing the response vary widely. This situation provides an excellent opportunity to learn from

a Corresponding author: bart.vonk@rws.nl

DOI 10.3311/FLOODRisk2020.19.7 each other and to work towards a commonly developed practice at a higher level.

In the last few years various international relationships have developed, illustrating that international co-operation on flood emergency response provides benefits to all organisations involved. Subsequently and in line with this, in the Netherlands the initiative came forward to jointly write an International Handbook for Emergency Response Measures for Flood Risk. This paper is an invitation to join forces to do so.

\section{The Handbook}

As a first stepping stone, the intention is to arrive at an annotated table of contents for this International Handbook. Underlying is the objective to also identify links to existing and potential users (communities), and to investigate their needs and wishes, and how these may be addressed in the Handbook. Such needs and wishes not only would refer to the contents of the handbook, but also as to how the contents are derived (process) and how these will be shaped (web-based? hardcopy? interactive?). We see this paper and the FLOODrisk 2020 Conference as an 
important step in an iterative process to arrive at a team that will progress and ultimately write the contents of the International Handbook for Emergency Response Measures for Flood Risk.

In the following, initial thoughts on the Handbook are presented. It goes without saying that many aspects are still open for discussion. As time progresses, we hope to reach consensus with those involved as to what is required; hence making sure we meet the needs of the target audience, making sure that those involved understand each other and work along commonly agreed lines and providing inspiration and good practices from various countries.

\subsection{Why do we need a Handbook?}

Flood emergency response is a complex issue. Actual flood events have triggered the development of new concepts and tools to aid responses. These cover both crisis management as well as the more technical aspects, such as emergency response measures. Although numerous initiatives have been taken to arrive at coherent approaches and to learn from each other, it can be noted that there is no single international initiative that provides an integrated overview of flood emergency response.

Furthermore, the scale of flood events potentially requires countries to help each other. The diversity and rareness of such events underlines the need to learn from each other. Whether it is helping each other or learning from each other, it is extremely important that all involved speak the same "emergency response language" and use compatible techniques and approaches as well as follow similar procedures.

Finally, there are various innovations and good practices across the globe that can be shared. As financial resources and manpower are often limited, by showcasing such practices and innovations, others can be inspired and can benefit from valuable lessons learnt elsewhere.

Therefore, we feel there is ample basis to jointly write an International Handbook, which is intended for the socalled "cold" (preparation) phase and should aid users to be prepared for the "warm" (actual flooding) phase, and which is a step beyond presently existing good practice documents like (JRC, 2019).

In the following sections an initial outline is presented of the contents of the handbook. In each following section the main topics are highlighted in a textbox, after which some of the underlying background to these topics are introduced.

\subsection{Focus}

Main topics:

- Threats of floods - types and their characteristics

- Flood defences - types, organisational aspects, failure mechanisms, prevention and breach limiting measures

It is essential to first define the type of flood threats and types of flood defences that need to be addressed in the Handbook. Defining the threats that are to be considered helps to identify and describe the characteristics that are critical for emergency response: lead times, durations and potential impacts. Linking this to the types of flood defences will then provide a clear picture regarding the infrastructure that requires emergency response, as well as feasible and realistic responses that can be made available. This will also help to define the target audience.

\subsection{Flood Emergency Response Management Principles}

Main topics:

- Framework, organisation, policies, planning, communication

- Readiness \& Preparedness

- Event \& Crisis management

It is important to provide the wider context of flood emergency response management. This covers organisational aspects, including the policies that provide the basis and how this is translated to staffing, planning and operationalisation of the emergency response processes.

The crisis management cycle will be described in detail, making sure that a framework is presented with commonly agreed concepts and protocols. In this respect it is also important to understand the different prevention and protection infrastructures, as these provide important starting points and requirements for preparedness and the response needed.

The description of the different flood emergency response management principles helps to define the target audience for the Handbook.

\subsection{Flood defence related aspects}

Main topics:
- Inspections
- $\quad$ Failure mechanisms
- Emergency measures

The flood emergency response is generally triggered by warnings, both outside (e.g. levee inspections) and inside (e.g. forecasts). These can vary from damage to a defence (e.g. significant erosion or deformation, cracks, piping, animal activities) to concluding that a warning threshold will be exceeded (e.g. overtopping) such that the defence is likely not to withstand the forecasted (e.g. hydraulic) load. Once this is defined, expected failure mechanism(s) can be defined. Thereafter the appropriate response measures can be formulated, varying from applying traditional sandbags to more innovative or specialist measures.

It should be noted that a robust approach to the maintenance of the flood defence infrastructure and the appropriate preparedness level of the flood defence manager will provide a sound basis of the inspections. We observe that more and more efforts are dedicated to defining the actual strength of flood defences. Such knowledge contributes to efficiently prepare and plan 
required response actions as to make the response more efficient and effective.

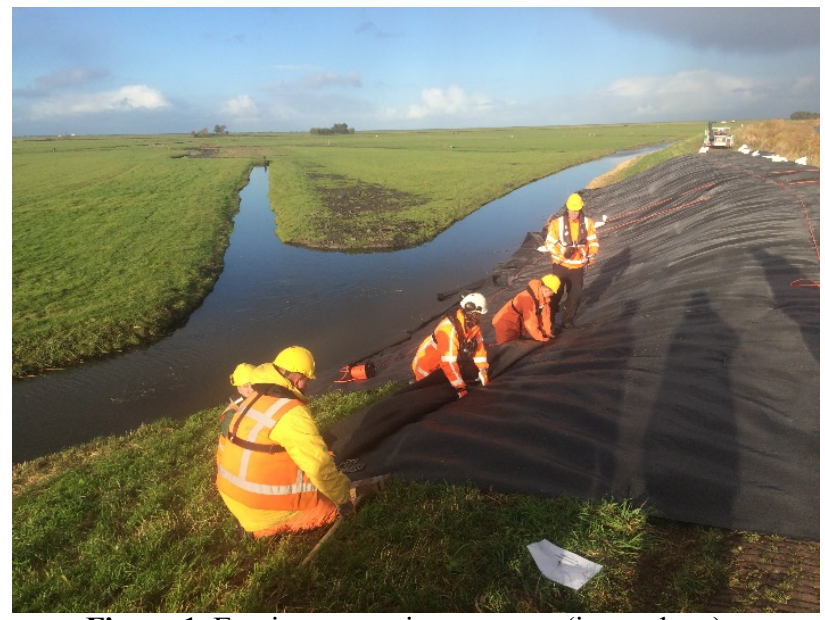

Figure 1. Erosion protection measure (inner slope).

\subsection{Practical considerations}

\section{Main topics:}

- Technical equipment and tools

- Logistics \& implementation

- Health \& Safety

The choice of an emergency response measure is complex. Such choices need to take into account issues such as time pressure, limited field data, the availability of materials and the combination with various other activities and choices that all need to be executed in parallel. The potential risks, local conditions, weather, limited resources and the overall demand for response measures, make it important to prioritise and to plan for the logistics.

When implementing measures, health \& safety aspects require ample attention. An injury or incident during the execution of emergency response activities require attention and energy of staff, which results in delay in the execution of measures. In particular as events are generally quite rare, health \& safety requirements often do not get the proper attention.

\subsection{Arriving at an effective and efficient integrated approach}

Main topics:

- Reliability of all aspects (combined!)

- Learning from and helping each other

Coming back to what is stated in Section 2.3, it should be realised that the implementation of an emergency response measure is part of a bigger picture. A measure can only be implemented efficiently and effectively when all aspects are properly managed. Therefore, the Handbook will devote ample attention to the reliability of the response, including the actual measure taken. This can be done at both strategic and operational levels.

With the strategic approach levels of maturity of the emergency response organisation can be defined. In other words: along which lines, or competencies, can the level at which an organisation can deal with a flood event challenge be defined.

An operational approach would be to zoom in on the measures themselves and to assess how measures contribute to minimizing the flood risks and even meeting for example nationally adopted targets / norms. The making of the Handbook could be instrumental to arrive at an approach to carry out such assessments.

Both approaches will definitely aid the process of learning from each other. In addition, use can be made of existing practices such as provided in the EU Civil Protection Mechanism (see Section 4).

\subsection{Summarized}

In the following the provisional table of contents is given. It goes without saying that both contents and sequence of chapters possibly may be more effective if presented in a different order. In brief the objectives overlying the Handbook can be summarized as follows:

- Building upon existing frameworks, described commonly accepted methods, approaches and proven practices regarding flood emergency response;

- To document good practices and provide guidance on how to learn from each other;

- To identify relevant knowledge, experiences and tools (as well as gaps).

Foreword

Acknowledgements

1. Introduction

2. Flood Emergency Response Management

3. Readiness \& Preparedness

4. Event \& Crisis management

5. Types of threats for flooding

6. Types of Flood Defences

7. Flood Inspections

8. Failure Mechanisms

9. Technical equipment and tools

10. Response and techniques for intervention

11. Logistics \& Implementation

12. Health \& Safety

13. Reliability of techniques for intervention

14. Learning from and helping each other

15. Concluding remarks

Glossary

Abbreviations

Literature

Figure 2. Provisional Table of Contents. 


\section{Nothing is cast in stone}

As mentioned, the contents and approach to arriving at the Handbook are subject to discussion and agreement. In the following some key discussions are raised that we feel need to be addressed.

\subsection{Discussion issue 1 - target audience}

The Handbook will be aimed at practitioners in the field of flood risk management / flood disaster risk reduction and will be of use to the following audience:

- Owners and managers of both flood defences and water regulating structures, such as dams and (retention) reservoirs

- Specialists in the field of flood emergency response

- $\quad$ Flood fighters

- Crisis managers

The specialists concern specialists in the field of water system behaviour (hydraulics, hydrology), geotechnics \& civil engineering, coordination, communication and in the various response activities (e.g. implementation of measures to prevent failure from happening).

The audience covers practitioners working in the public sector (e.g. national, regional and local water authorities, civil defence actors), the private sector (e.g. consultants, contractors, suppliers), NGO's as well as in the academic world (e.g. research institutes).

The ambition with targeting such a wide audience is quite substantial. Reason for this is that an integrated approach requires involvement of many target groups. Possibly it would be good to provide a reader per chapter to help the reader assess whether that chapter is relevant for him / her.

Alternatively, focus can be put on a more defined target audience, e.g. practitioners involved in flood defences related emergency response. This would imply that matters related to e.g. evacuation are not addressed.

\subsection{Discussion issue 2 - scope: type of threats}

Different types of threats should be addressed in the Handbook. Current thoughts are to cover storm surges, river flooding and pluvial flooding. Regarding river dynamics, it is suggested to cover a broad array of flood threats, ranging from slower processes (rivers fed by snowmelt) to quicker ones (rainfed rivers) and even flash floods.

The question is whether to also address other types of threats. Examples are landslides or floods caused by earthquakes and tsunamis.

\subsection{Discussion issue 3 - scope: type of defences}

The following types of flood defences are suggested to be addressed in the handbook:

- Levees;

- Dams \& barriers;

- Structures with a flood defence function (e.g. locks, sluices and weirs);
- Demountable \& Temporary Defences.

Storm surge barriers are not included in this present scope. Background for this is that the scale of such barriers requires a very different approach regarding emergency response measures. There is some arbitrariness in this choice and suggestions are always welcome.

By including dams, valuable developments that have been pursued in an ICOLD context (see ICOLD, 2017, to give just one example) can be addressed and included as well.

\subsection{Discussion issue 4 - how to present}

It is suggested to present the Handbook in a digital environment. As an additional thought, the Handbook could also be presented in a Wiki type environment on the internet. This would not only have the advantage to have a platform where all contents of the handbook are displayed, but such a platform also facilitates active engagement with the Handbook community, e.g. to jointly develop and include new approaches.

Attention needs to be given on how matters are presented in an easily readable fashion. In the Netherlands we have started documenting lessons learned in a factsheet format, using illustrations and in any case forcing ourselves to make the lessons learned explicit (see Figure 3 ). However other approaches may be more effective.

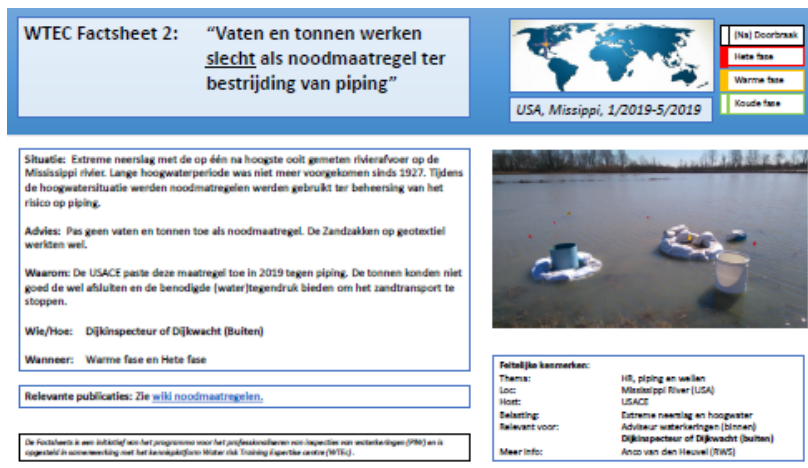

Figure 3. Example Factsheet (in Dutch)

\subsection{Discussion 5 - how can the Handbook help in (international) co-operation?}

To arrive at the Handbook means that a 'coalition of the willing' needs to be established, of which members are able to contribute. It can be stated that such a Coalition/ Community is in itself an objective! By joining forces and jointly documenting the various chapters, members will be enabled to actively arrive at commonly agreed approaches and thus highlight at what is the general consensus regarding good practices.

The question however is how far such discussions should go. Time is scarce, and above all costly, requiring those involved to make choices as to how to efficiently arrive at commonly agreed information in the Handbook. 


\section{Requirements to help each other}

When flood disasters strike, response teams, technical equipment and other resources need to be deployed in the shortest time possible at the right location in order to to support the flood emergency response efforts. Being well prepared to intervene immediately in a disaster is crucial in saving lives and minimising damage.

A joint approach helps to pool expertise and capacities of first responders, avoids duplication of relief efforts and ensures that assistance meets the needs of the flood defence manager and thus of those affected.

Pooling together civil protection capacities and capabilities results in a stronger and more coherent collective response. We are convinced that the Handbook will be an invaluable tool to aid such processes. Reference can be made to mechanisms in place, such as the EU Civil Protection Mechanism. Please refer to the textbox below and to the factsheet that can be found on:

https://ec.europa.eu/echo/what/civil-protection/mechanism.

The overall objective of the EU Civil Protection Mechanism (See Factsheet on

https://ec.europa.eu/echo/what/civil-

protection/mechanism) is to strengthen cooperation between the EU Member States and 6 additional socalled Participating States (i.e. Iceland, Norway, Serbia, North Macedonia, Montenegro, and Turkey) in the field of civil protection, with a view to improve prevention, preparedness and response to natural or man-made disasters.

When the scale of an emergency overwhelms the response capabilities of a country, it can request assistance. Through the Mechanism, the European Commission then can play a key role in coordinating the response to disasters in Europe, or to any other country or international organisation asking for help. As part of the Mechanism, the Emergency Response Coordination Centre (ERCC) monitors events around the globe 24/7 and ensures rapid deployment of emergency support through a direct link with national civil protection authorities. A range of specialised teams and equipment can be mobilised at short notice for deployments inside and outside Europe.

Since its inception in 2001, the EU Civil Protection Mechanism has responded to over 330 requests for assistance inside and outside the EU.

The Mechanism also helps to coordinate disaster preparedness and prevention activities of national authorities and contributes to the exchange of good practices. This facilitates both the achievement of higher common standards and an interchangeable and compatible way of working when a disaster strikes.

Figure 4. Example - EU Civil Protection Mechanism.

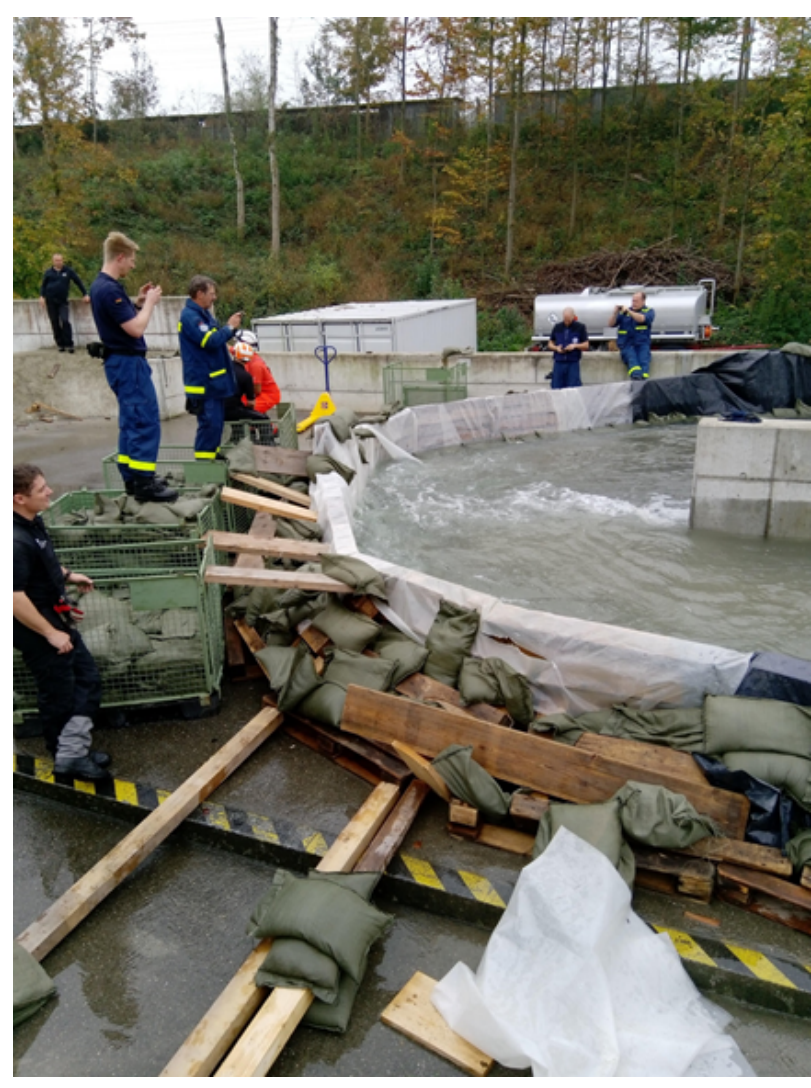

Figure 5. Practical Exercise in Switzerland voor Flash Flood Advisors (October 2019).

\section{Living Lab}

One recent example where parties from different countries have joined forces is the Belgian/Dutch project Living Lab Hedwige and Prosperpolder (Interreg Polder 2 Seas Mers Zeeën: Polder2Cs). In this Interreg project, professionals from Belgium, The Netherlands, France and the UK have joined forces to experiment on climate adaptive flood defences and emergency response activities. This project already delivered a study on risk perception, a framework for emergency response during extreme events, an initial version of an inspection app called "APP2C" and experiments with innovative temporary solutions to repair damages caused by overflow of a flood defence.

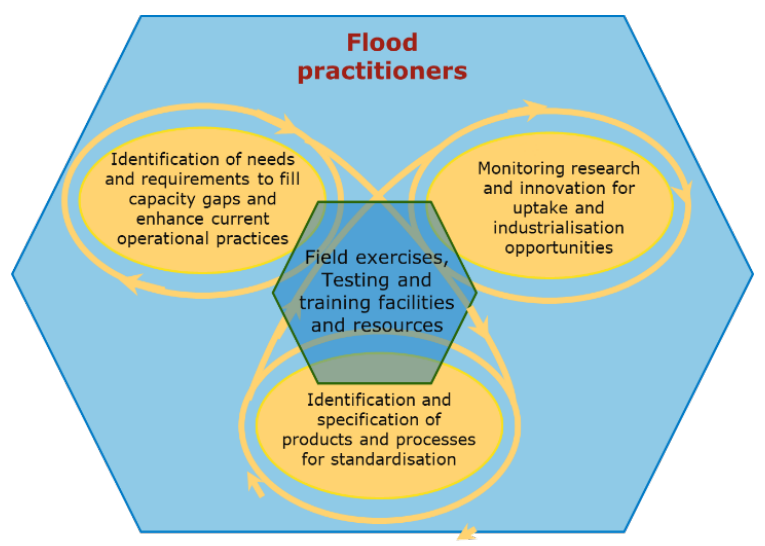

Figure 6. Processes linked to the initiative. 
This project, which continues till the end of 2022, can offer a significant contribution to the Handbook, as it creates a unique opportunity for full-scale experiments and exercises in order to connect practice and policy (see also Figure 5). Potentially, other initiatives like test and training sites or flood fighting crisis exercises in the different participating countries can provide useful contributions as well.

\section{Arriving at a coalition}

A coalition of the willing is essential as to arrive at the Handbook. Undoubtedly during its development those involved will have inspiring discussions that are needed to meet the aforementioned ambitions. This in itself is an attractive opportunity to learn from each other.

It will be important to arrive at an efficient organisation of this coalition. We propose to work with a project management team, whose tasks are to safeguard meeting planning deadlines and to ensure that the right people are involved at the right moments in time. Such a team would typically include the lead editors. For each of the chapters we foresee a small team of authors (say maximum of 4) and reviewers. As mentioned, we expect there is sufficient interaction between the authors: experienced professionals that have an intimate knowledge of the topic at hand.

At present we already have soft commitment from several organisations, such as the US Army Corps of Engineers (USA), the Environment Agency (England) and the Technisches Hilfswerk (Germany). We are keen for other countries / organisations to join us.

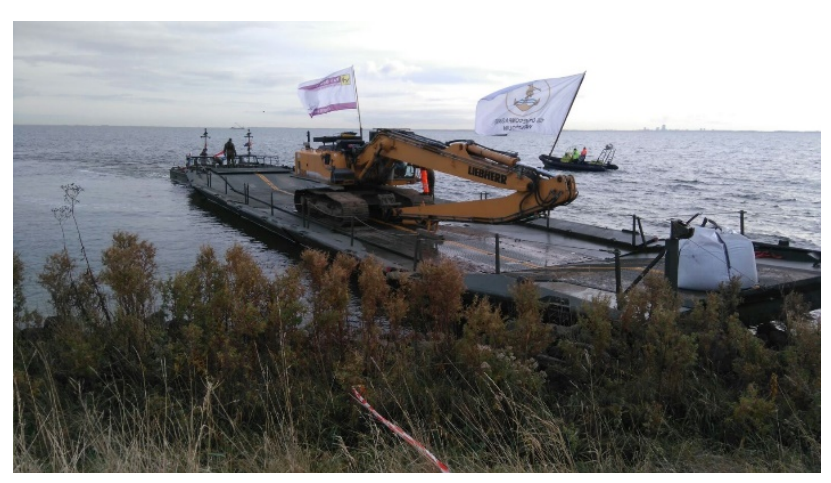

Figure 7. Exercise Waterwolf, Marken, The Netherlands, 2-4 November 2016: placing of Big Bags by the military.

We would like to mention that we trust that all involved parties are able to contribute at their own costs. Assuming that the process requires less than two years of time and with modern communication (including the recent developed experience with working online - due to the COVID19 pandemic), costs should be quite limited. It goes without saying that budget estimates will be made in the initial phases, such that parties can take a decision on whether they want to join or not.

Ideally, this coalition will grow into an active community of practice in the long run. As mentioned earlier, we feel that joining forces internationally is a way to get access to the good practices the world has. A longterm approach will safeguard this, and will no doubt provide new opportunities.

\section{Concluding remarks and next steps}

We are convinced that the Handbook for Emergency Response to Flood Risk can provide an internationally recognised integrated overview of flood emergency response measures. In this paper we have presented some initial thoughts on this initiative. We are fully aware that this still needs revisiting. Also numerous topics as well as practical aspects related to the handbook have not been touched in this paper. In that respect this paper is an open invitation to join us in this coalition of the willing.

During the FLOODrisk 2021 Symposium we are happy to discuss with you how we may go about it. To this end we have been allocated a so-called Special Session. During the event we want to gauge interest, arrive at an initial coalition based on soft commitment and basically try to make sure that we are confident that the coalition has the width and depth to deliver the handbook. We are also aware that various aspects related to the process ahead of us should be outlined, such that all are aware of the journey that lies ahead in arriving at the handbook.

Soon after FLOODrisk 2020 we will organise a first meeting (likely via video conferencing technology) to firm up on matters, including commitment and various practical aspects. Examples are shape and form of the Handbook, hosting and publishing. Thereafter, aforementioned journey should be clear to those involved.

\section{References}

1. CIRIA (2013). The International Levee Handbook, London, United Kingdom.

2. European Commission (2020). Factsheet on EU Civil Protection Mechanism, available online: https://ec.europa.eu/echo/what/civilprotection/mechanism

3. ICOLD (2017). Management of dam incidents. ICOLD European Club, Working Group on dam incidents.

4. JRC (2019). Science for disaster risk management 2017, Joint Research Centre of the European Commission

5. SBRCUR (2018). Handboek Uitvoering Dijken. Chapter 7. Utrecht, The Netherlands.

6. WMO (2009). Integrated Flood Management Concept Paper. Geneva, Switzerland.

7. WMO (Feb 2011). Integrated Flood Management Tool Series. Flood Emergency Planning. Issue 11. Geneva, Switzerland.

8. Interreg Polder2Cs Living Lab HedwigeProsperpolder $\mid$ Polder2C (polder2cs.eu) 